\title{
Kinetic study of the regeneration of spent caustic via the genetic algorithm method
}

\author{
Asadollah Karimi $^{1}{ }^{\mathbb{D}}$, Esmaeil Fatehifar ${ }^{2 *}{ }^{\mathbb{D}}$, Reza Alizadeh $^{2}$, Hadi Soltani $^{3}$ \\ ${ }^{1}$ Department of Chemical Engineering, Faculty of Engineering, University of Maragheh, Maragheh, Iran \\ ${ }^{2}$ Environmental Engineering Research Center, Faculty of Chemical Engineering, Sahand University of Technology, Tabriz, Iran \\ ${ }^{3}$ Department of Chemical Engineering, Ahar Branch, Islamic Azad University, Ahar, Iran
}

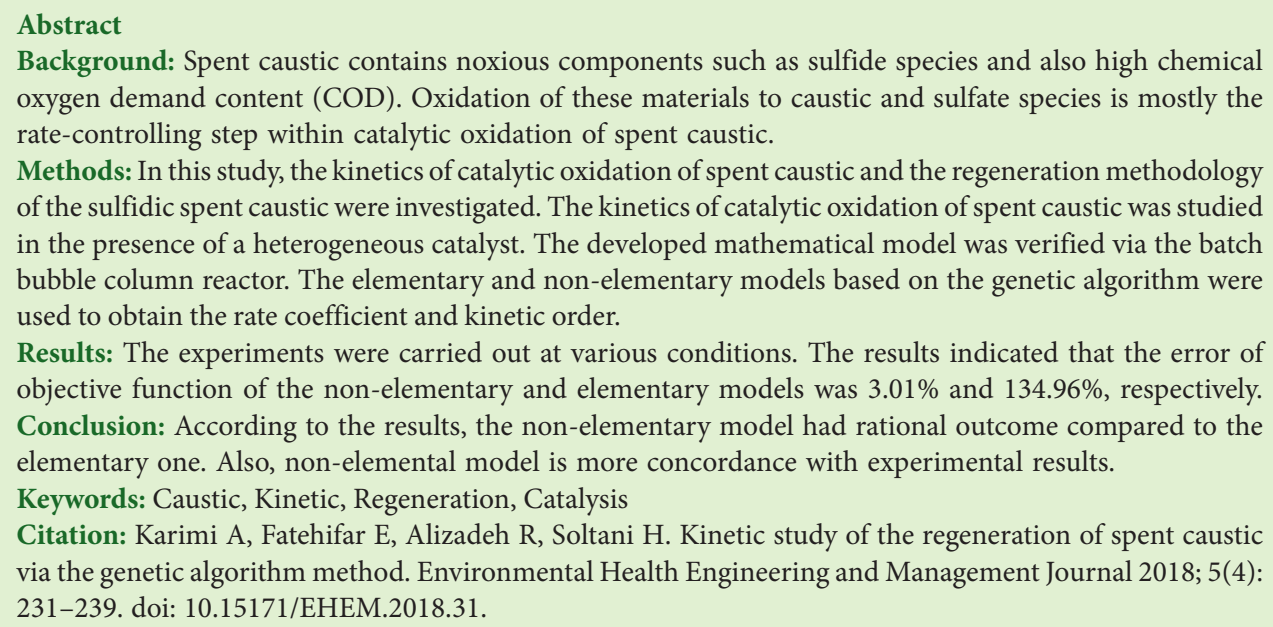

\section{Introduction}

Chemical industries are among those fields which create various kinds of organic and inorganic waste in varying concentrations that must be treated. The contamination of these wastes is not only limited to water, air, soil and noise, but also has extended to the human's life $(1,2)$. The petrochemical plants are among those industries that generate all kinds of wastewater. The aqueous caustic solutions are usually applied for the removal of impurities, like sulfur compounds and carbon dioxide in petrochemical plants such as the olefin unit (3). The effluent of caustic scrubbing as a waste solution is known as spent caustic. Spent caustic is a highly deadly and odorous waste. According to the US Environmental Protection Agency (EPA) reports, spent caustic is categorized as a hazardous and deleterious waste in the olefin unit (4). Table 1 shows some characteristics of spent caustic from the olefin unit in a petrochemical plant.

There are a couple of methods for treating spent caustic, such as incineration, disposal and oxidation methods, among which chemical oxidation is very practical and applicable (5). Some prominent methods are wet air oxidation (WAO), advanced oxidation process (AOP) and catalytic oxidation process (COP) that have been applied to treat spent caustic wastewater (6-14). WAO is carried out at high temperature and pressure depending on feed. Often, WAO is applied for pre-treating of spent caustic and it cannot lower the chemical oxygen demand (COD) of spent caustic to desired effluent (15). Therefore, it is necessary to use catalytic wet air oxidation (CWAO). Treatment of spent caustic wastewater was studied in catalytic reactor with graphene oxide (GO) and ruthenium/ GO catalysts (16). AOP can be defined as the acceleration of an oxidation reaction by generation of hydroxyl radicals. Also, AOP are defined as processes which treat wastewater steams with high COD and toxic contaminants (17). An AOP system involves a catalyst (photo-catalysis) and an oxidant such as $\mathrm{H}_{2} \mathrm{O}_{2}, \mathrm{O}_{3} / \mathrm{H}_{2} \mathrm{O}_{2}$, fenton, and UV. A novel photocatalytic reactor was studied for the treatment of spent caustic wastewater and $\mathrm{TiO}_{2}$-clinoptilolite was synthesized for the enhancement of its photocatalytic efficiency (18). COP is used to remove sulfide compounds from the spent caustic wastewater. In the previous study, spent caustic wastewater of an olefin unit was treated in 
Table 1. Characteristics of spent caustic produced by Olefin unit

\begin{tabular}{ll}
\hline Item & Value \\
\hline Total sulfur & $14000-21000 \mathrm{mg} / \mathrm{L}$ \\
$\mathrm{COD}$ & $15000-30000 \mathrm{mg} / \mathrm{L}$ \\
$\mathrm{pH}$ & $13.5-13.7$ \\
$\mathrm{~S}^{2-}$ & $670 \mathrm{mg} / \mathrm{L}$ \\
\hline Phenols & $300 \mathrm{mg} / \mathrm{L}$ \\
Specific gravity & 1.1 \\
$\mathrm{NaOH}$ & $1-3 \mathrm{wt} \%$ \\
\hline
\end{tabular}

two reactor (the system can be represented via a series of bubble column reactor with mixed reactor) by the catalytic chemical oxidation method (19). This waste stream was finally regenerated and recycled to the unit. In the present study, the global reaction kinetics were modelled and optimized in a bubble column reactor via genetic algorithm (GA). Analysis of the kinetic models of catalytic reactions requires more accurate estimation of rate parameters and constants (20-22). The most commonly used methods in determining the optimal parameters model, are non-linear fitting algorithm like artificial neural networks and Marquardt algorithm. But, the structure of non-linear reaction kinetics treatment of spent caustic has more than one relative minimum value. So, it is difficult to achieve the optimal point by using these methods. One way to solve such kind of problems is the use of randomized algorithms. As a new method, GA has been introduced for optimization of non-linear models (23-25). Various applications of GA have been proposed in non-linear models to determine the optimal parameters. The flexibility of genetic algorithm is its major advantage which provides the objective function and constraints in farming (24). It can be seen that researchers have used GA to estimate the amounts of kinetic parameters of complex reactions. Finding a general kinetic model for hydrogenolysis of dibenzothiophene (DBT) based on Langmuir-Hinshelwood type (26), and estimating simultaneously the kinetic as well as energetic parameters of the complex reaction of the saponification of ethyl acetate (27) are examples of the use of genetic algorithm in these cases. In this study, a bench-scale pilot was employed for regenerating and treating spent caustic. The development of global reaction of spent caustic is the main purpose of this work. Another purpose of this study was to investigate the application of GA to choose a precise kinetic model and determine the optimal parameters. The parameters of this reaction are rate constants and kinetic order of concentrations. The kinetics of the reaction was surveyed as a global reaction in a bubble column reactor. This function objective is prediction error of the model and the experimental concentration. The kinetic steps are shown in Figure 1.

\section{Materials and Methods}

Experimental procedure

The waste solution was provided by a petrochemical plant

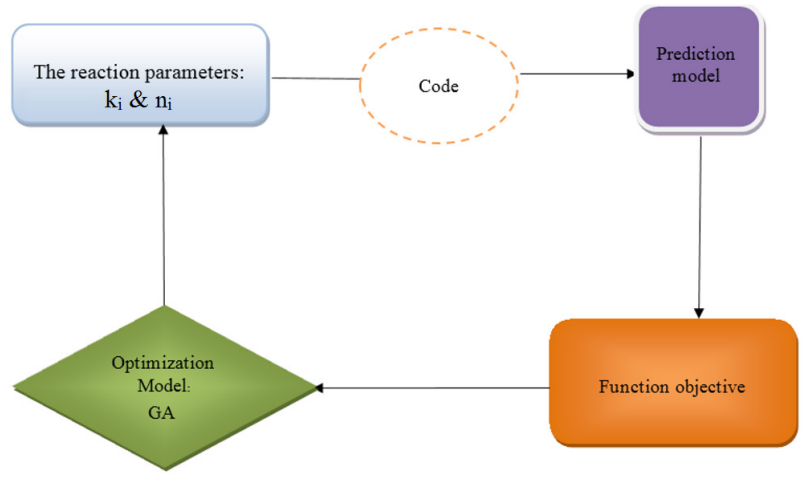

Figure 1. The flowchart of the overall kinetics.

(Olefin unit) in Iran. The catalytic chemical oxidation was conducted to regenerate and treat spent caustic in a bubble column reactor, with capacity of $500 \mathrm{ml}$ and $40 \mu \mathrm{m}$ pore size (Figure 2). IVKAZ catalyst of the JSC company was employed to regenerate spent caustic in a bubble column reactor. The reactor was operated at ambient pressure and $90^{\circ} \mathrm{C}$. In previous work, the treatment of spent caustic was accomplished in two reactors by the full factorial design (19). It has been found that the optimal operating temperature and air flow for treatment and regeneration of spent caustic were 85 to $95^{\circ} \mathrm{C}$ and $10 \mathrm{~L} / \mathrm{min}$, respectively, while temperature of $90^{\circ} \mathrm{C}$ and air flow of $10 \mathrm{~L} / \mathrm{min}$ were chosen for this kinetic study.

All the demanded materials purchased from Merck Chemicals were used for data analysis procedure. The mercaptide and hydrosulfite sodium were measured using a digital pH meter (Metrohm). These compounds were determined according to ASTM-UOP 209. Thiosulfate was measured using a spectrophotometer. The standard thiosulfate titrant and standard iodine titrant, $\mathrm{HCl}$ and indicator were used for the titration of $\mathrm{S}^{2-}$ and alkalinity, respectively. The alkalinity, $\mathrm{S}^{2-}$ and $\mathrm{O}_{2}$ of the spent caustic were analyzed by standard methods for the examination of water and wastewater (28). All solutions were prepared using deionized water.

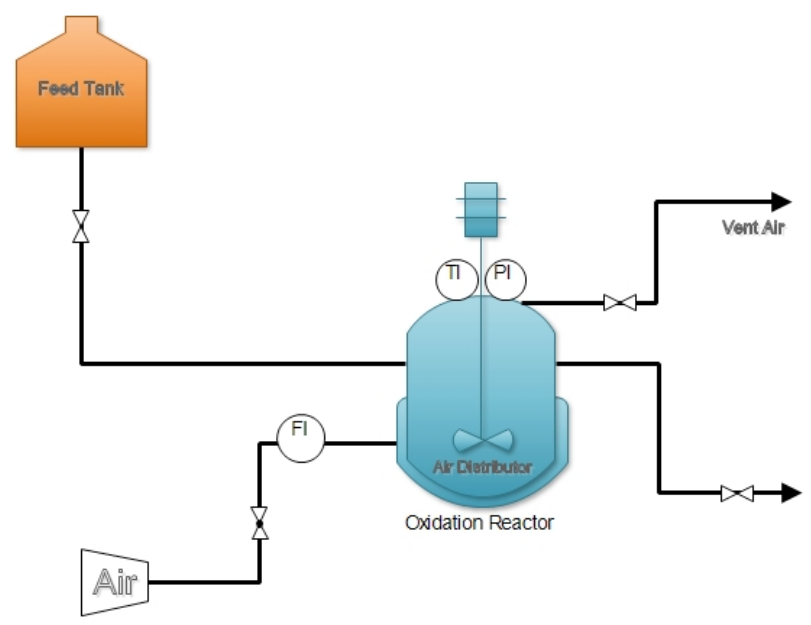

Figure 2. The Schematic of bench scale pilot. 


\section{Kinetic modelling}

Spent caustic contains a wide variety of compounds, each one has its own specific kinetic characteristics. In the majority of the reactions ( 1 to 5 ), thiosulfate was produced as an intermediate compound. Several previous studies have shown that thiosulfate converts to sulfate in an alkaline environment at $76-85^{\circ} \mathrm{C}$. The reaction rates 1 to 5 was considered as both elementary and non-elementary reactions. The GA method was used for each of the reactions. Table 2 indicated the reaction rate equations. The reaction rate equations of $a, b, c, d$, and $f$ belong to caustic, thiosulfate sodium, oxygen, hydrosulfite sodium, mercaptide, and sodium sulfide, respectively.

As air flow enters during the process, the reactor is a semi batch. It is assumed ideal for studying the reaction kinetic $(29,30)$. The bubble column reactor was considered as a batch reactor. For this purpose, the oxygen injection was computed every 5 seconds and the total amount has been added in 20, 25, and 30 minutes.

In - Out $+r_{i}^{*} V=d\left(C_{i}^{*} V\right) / d t$

Where $r_{i}$ is the rate of reaction for i material, $\mathrm{V}$ is the volume of the batch reactor and $t$ is time.

Oxygen is the only component which enters the reactor and other ones have no entery or exit flow. The solution volume $(\mathrm{V})$ is not constant due to high evaporation especially at high temperatures. To solve this problem, the reaction time is divided to shorter intervals (some seconds) and the output of each interval assumes as the input of the next interval. This technique removes the input and output terms from equation 6 as mentioned below:

1- At the beginning of each interval, it is assumed that the total amount of oxygen which was supposed to enter the reactor gradually, is injected at the beginning.

2 - As the reaction time is divided to shorter intervals, the volume variations at these intervals will be small enough to be neglected. It is worth noting that the shorter intervals to be considered, the error of this method will be less. In this way, the equation 7 is rearranged as follows:

$\mathrm{r}_{\mathrm{i}}=\mathrm{d}\left(\mathrm{C}_{\mathrm{i}}\right) / \mathrm{dt}$
In this study, the following steps were performed to determine the kinetic parameters. At first, members of the primary population including constants of reactions and kinetic order of reaction were generated in a completely random manner, depending on the range of defined changes. This vector consists of seventeen variables and five variables for non-elementary reactions and elementary reactions, respectively. An example of these vectors is $\mathrm{V}_{\mathrm{i}}=\left(\mathrm{k}_{1} \mathrm{k}_{2} \mathrm{k}_{3} \mathrm{k}_{4} \mathrm{k}_{5} \mathrm{X}_{6} \mathrm{X}_{7} \mathrm{X}_{8} \mathrm{X}_{9} \mathrm{X}_{10} \mathrm{X}_{11} \mathrm{X}_{12} \mathrm{X}_{13} \mathrm{X}_{14}\right.$ $\left.\mathrm{X}_{15} \mathrm{X}_{16} \mathrm{X}_{17}\right)$ for non-elementary reaction and $\mathrm{V}_{\mathrm{i}}=\left(\mathrm{k}_{1}^{\prime} \mathrm{k}_{2}\right.$ $\mathrm{k}_{3}^{\prime} \mathrm{k}_{4} \mathrm{k}_{5}$ ) for elementary reaction. The range of variables changes inside the vectors were between $\left(10^{-3}-10^{+1}\right)$ and population size was 500 .

The objective function is defined as the minimum error model results and the experimental results. The error of objective function is shown in equation 8 .

Error $=\frac{1}{n} \sum_{i=1}^{n} \frac{\left|C_{i}^{\exp }-C_{i}^{c a l}\right|}{C_{i}^{\exp }} * 100$

After generating the initial populations via the GA, the value of the objective function of each member is calculated. By using the objective function values based on the roulette wheel method, members are ranked. Obviously, any member with a better objective function will be considered more valuable. GA operators are reproduction, crossover and mutation $(31,32)$.

Reproduction: By this operator, $50 \%$ of the members of the current generation based on the roulette wheel are transferred to the new generation as follows:

I) Based on elitism: The best members of the current generation $(5 \%)$ are transferred to the new generation directly (and not randomly),

II) $45 \%$ of the members are randomly assigned to the new generation (30).

Crossover: To produce new generation by the crossover operation, both one- and two-point crossovers are employed. After selecting two vectors by the roulette wheel, a random number is generated to decompose the chromosome (i.e. the vector) into several pseudo parents. Then, these parents are composed together to

Table 2. The equation rate of the reactions (1 to 5 )

\begin{tabular}{|c|c|c|c|}
\hline & Non-elementary & & Elementary \\
\hline $1-$ & $\begin{array}{l}R_{a}=-k_{1} C_{a}^{X_{6}} C_{b}^{X_{7}} C_{c}^{X_{8}}-k_{2} C_{a}^{X_{9}} C_{c}^{X_{10}} C_{d}^{X_{11}}+2 k_{4} C_{e}^{X_{14}} C_{c}^{X_{15}}+ \\
2 k_{5} C_{c}^{X_{16}} C_{f}^{X_{17}}\end{array}$ & $1-$ & $\begin{array}{l}R_{a}=-k_{1}^{\prime} C_{a} C_{c} C_{b}^{0.5}-k_{2}^{\prime} C_{a} C_{c}^{2} C_{d}+2 k_{4}^{\prime} C_{e}^{2} C_{c}^{0.5}+ \\
2 k_{5}^{\prime} C_{c} C_{f}\end{array}$ \\
\hline $2-$ & $\begin{array}{l}R_{b}=-0.5 k_{1} C_{a}^{X_{6}} C_{b}^{X_{7}} C_{c}^{X_{8}}+0.5 k_{3} C_{d}^{X_{12}} C_{c}^{X_{13}} C_{d}^{X_{11}}+ \\
k_{5} C_{f}^{X_{17}} C_{c}^{X_{16}}\end{array}$ & 2- & $R_{b}=-0.5 k_{1}^{\prime} C_{a} C_{b}^{0.5} C_{c}+0.5 k_{3}^{\prime} C_{c}^{2} C_{d}+k_{5}^{\prime} C_{c} C_{f}$ \\
\hline 3- & $\begin{array}{l}R_{c}=-k_{1} C_{a}^{X_{6}} C_{b}^{X_{7}} C_{c}^{X_{8}}-2 k_{2} C_{a}^{X_{9}} C_{c}^{X_{10}} C_{d}^{X_{11}}-2 k_{3} C_{d}^{X_{12}} C_{c}^{13}- \\
0.5 k_{4} C_{e}^{X_{14}} C_{c}^{X_{15}}-2 k_{5} C_{c}^{X_{16}} C_{f}^{X_{17}}\end{array}$ & 3- & $\begin{array}{l}R_{c}=-k_{1}^{\prime} C_{a} C_{b}^{0.5} C_{c}-2 k_{2}^{\prime} C_{a} C_{c}^{2} C_{d}-0.5 k_{3}^{\prime} C_{d} C_{c}^{2}- \\
0.5 k_{4}^{\prime} C_{e}^{2} C_{c}^{0.5}-2 k_{5}^{\prime} C_{c} C_{f}\end{array}$ \\
\hline 4- & $R_{d}=-k_{2} C_{a}^{X_{9}} C_{c}^{X_{10}} C_{d}^{X_{11}}-k_{3} C_{d}^{X_{12}} C_{c}^{13}$ & 4- & $R_{d}=-k_{2}^{\prime} C_{a} C_{c}^{2} C_{d}-k_{3}^{\prime} C_{d} C_{c}^{2}$ \\
\hline 5- & $R_{e}=-2 k_{4} C_{e}^{X_{14}} C_{c}^{X_{15}}$ & $5-$ & $R_{e}=-2 k_{4}^{\prime} C_{e}^{2} C_{c}^{0.5}$ \\
\hline 6- & $R_{f}=-2 k_{5} C_{c}^{X_{16}} C_{f}^{X_{17}}$ & $6-$ & $R_{f}=-2 k_{5}^{\prime} C_{c} C_{f}$ \\
\hline
\end{tabular}


produce offspring. In this study, the rate of crossover was considered to be $50 \%$.

It is noteworthy that in this operator, it is possible to choose more members with a better objective function. Mutation: New generation of the present operation is used to all members after producing. The definition of the mutation and its rate plays an important role in the convergence of the algorithm. As a general fact, inappropriate definition of this operator leads to premature convergence of the GA. Therefore, mutation should be defined in such a manner that the GA has sufficient diversity during its evolutionary procedure. The mutation rate is based on the following equation: $\mathrm{Mu}=\mathrm{Mu}_{\min }+\left(\mathrm{Mu}_{\max }-\mathrm{Mu}_{\min }\right) \cdot \exp \left(-10^{*}\left(\mathrm{C}_{\mathrm{w}}-\mathrm{C}_{\mathrm{b}}\right) / \mathrm{C}_{\mathrm{w}}\right)$ Where $\mathrm{Mu}$ is the mutation rate, calculated in each generation. $\mathrm{Mu}_{\min }$ and $\mathrm{Mu}_{\max }$ are the minimum and maximum mutation rates allowed and their values are $10 \%$ and $100 \%$, respectively, in the equation $9 . \mathrm{C}_{\mathrm{w}}$ is the value of the cost of the worst individual and $C_{b}$ is the value of the cost of the best one (28). The flowchart of the applied GA method is shown in Figure 3.

Results

The concentrations of components in the bubble column reactor were obtained. As mentioned before, the temperature and flow rate of reaction were constant and only the reaction time changed. The experimental amount of each component is indicated in Figure 4-9. The value of spent caustic is illustrated for elementary and nonelementary models in Figure 4. At an earlier time (20 minutes), the elementary model can better predict the experimental results, also non-elementary model can be seen to be better with time.

The obtained results of thiosulfate sodium are demonstrated in Figure 5. As shown in Figure 5, the thiosulfate amount will be reduced by the increase of reaction time. The oxidation process of thiosulfate to sulfate is a heterogeneous gas-liquid reaction.

Figure 6 compares oxygen amount botained by experimental and GA methods. The real amount of

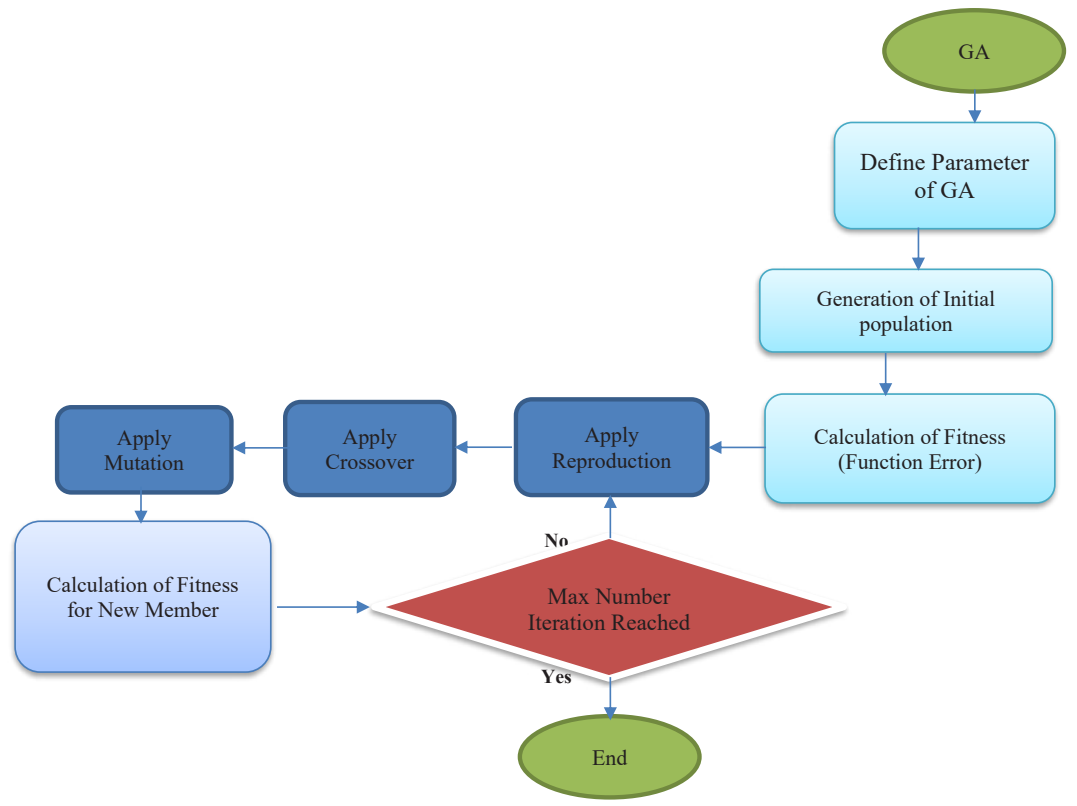

Figure 3. The diagram of genetic algorithm.

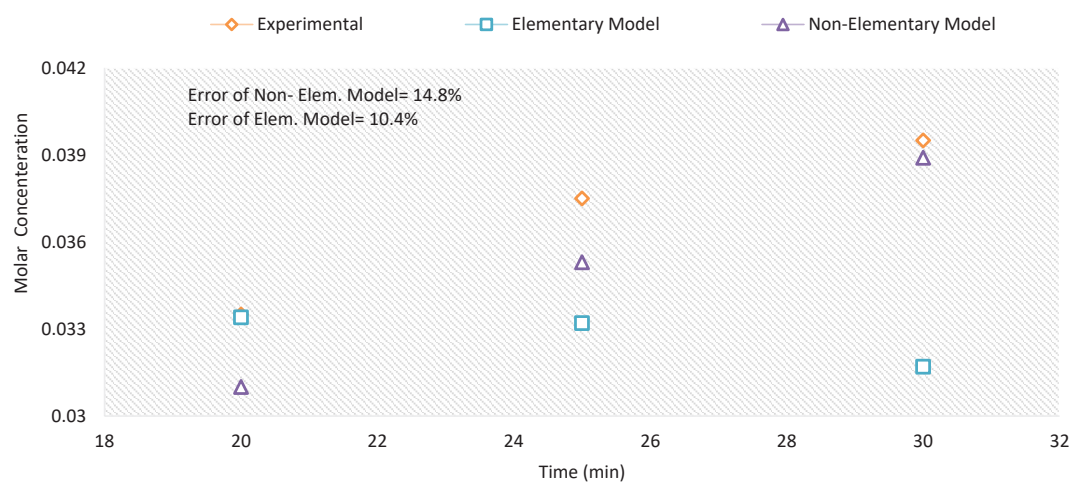

Figure 4. The results of caustic obtained from experimental data and kinetic model. 
oxygen has been computed based on the stoichiometric calculations in a $500 \mathrm{~mL}$ bubble column reactor. As shown in Figure 6, the results of the non-elementary model is near to the actual values.

According to the amount of NaHS shown in Figure 7, the elementary model is not a desirable model to predict experimentally-obtained results of NaHS. The hydrosulfite sodium is consumed in two different reactions, so the prediction of this component is difficult by the elementary model.

The oxidation of NaSR is illustrated in Figure 8. The nonelementary model has really low error compared to the

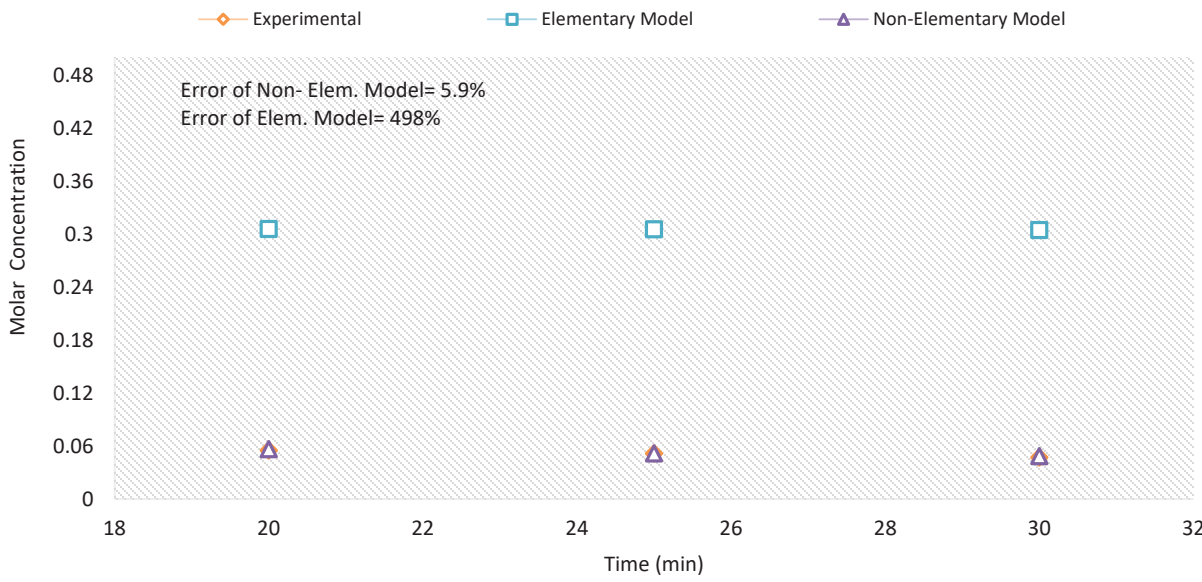

Figure 5. The results of thiosulfate obtained from experimental data and kinetic model.

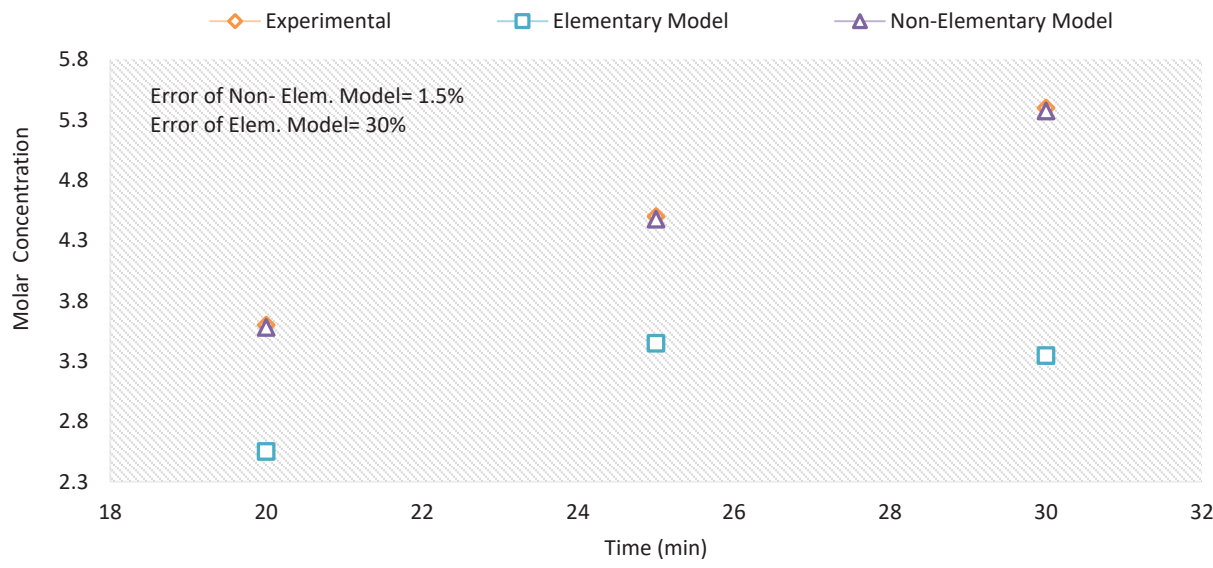

Figure 6 . The results of oxygen obtained from experimental data and kinetic model.

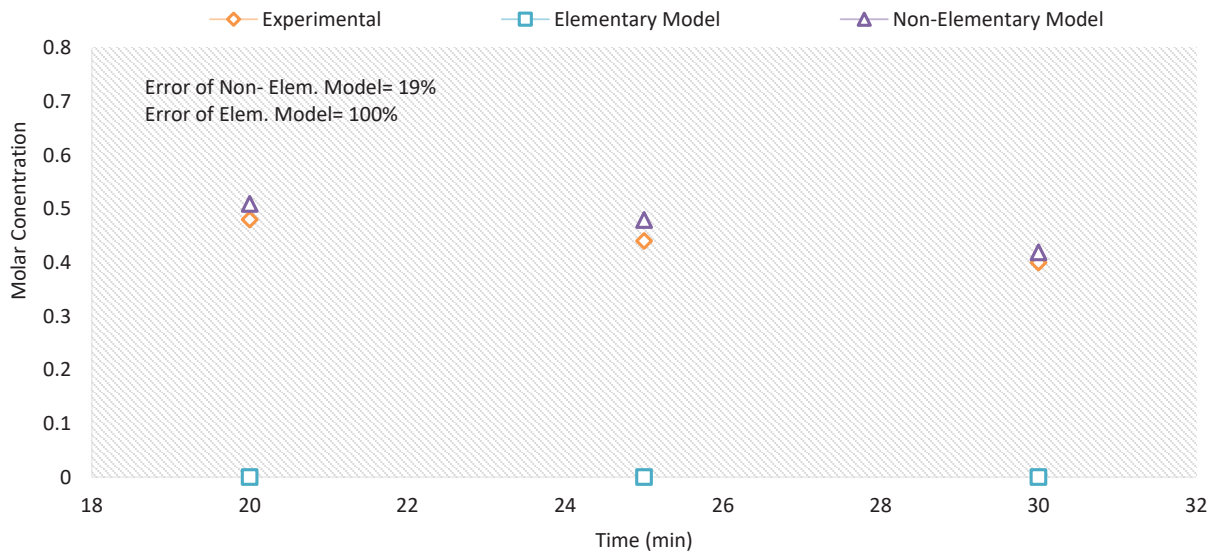

Figure 7. The results of NaHS obtained from experimental data and kinetic model. 


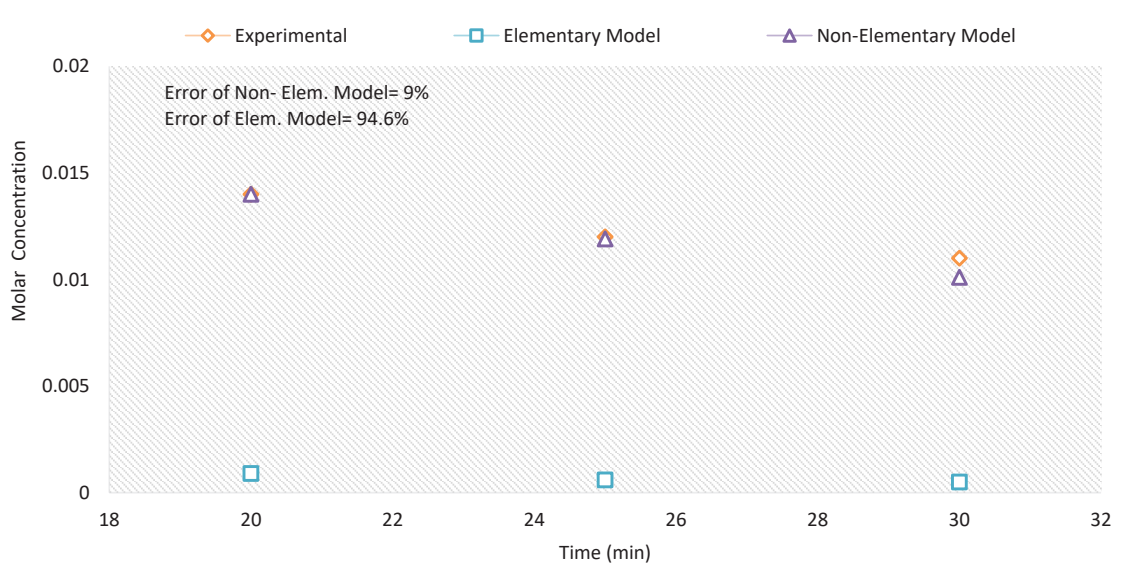

Figure 8. The results of NaSR obtained from experimental data and kinetic model.

elementary one. The results illustrate that non-elementary model is more concordance with experimental results (error of non-elementary model was lower than 10\%). The change of amount of $\mathrm{Na}_{2} \mathrm{~S}$ is indicated in Figure 9. The catalytic oxidation with increase of the reaction time, led to higher conversion of sulfides to thiosulfate, therefore, the amount of sulfide species reduced. The increase of reaction time helped approach the value of non-elementary model to the experimental amount and resulted in a low error at the end of the reaction time.

The kinetic coefficients obtained from elementary and non-elementary models are shown in Table 3. The kinetic coefficient of the reaction 4 had the highest value among other reactions. This value made the reaction rate much faster than the other reactions.

Table 4 indicates the order of concentration in the nonelementary model. These values were obtained by the GA method.

\section{Discussion}

Different chemical oxidation reactions took place in bubble column reactor. The main oxidation reactions of spent caustic are as follows (33):

$$
\mathrm{NaOH}+1 / 2 \mathrm{Na}_{2} \mathrm{~S}_{2} \mathrm{O}_{3}+\mathrm{O}_{2} \mathrm{Na}_{2} \mathrm{SO}_{4}+1 / 2 \mathrm{H}_{2} \mathrm{O}
$$

$$
\begin{aligned}
& \mathrm{NaSH}+2 \mathrm{O}_{2}+\mathrm{NaOH} \mathrm{Na} \mathrm{SO}_{4}+\mathrm{H}_{2} \mathrm{O} \\
& \mathrm{NaSH}+2 \mathrm{O}_{2} 1 / 2 \mathrm{Na}_{2} \mathrm{~S}_{2} \mathrm{O}_{3}+1 / 2 \mathrm{H}_{2} \mathrm{O} \\
& 2 \mathrm{RSNa}+1 / 2 \mathrm{O}_{2}+\mathrm{H}_{2} \mathrm{O} \text { RSSR }+2 \mathrm{NaOH} \\
& \mathrm{Na}_{2} \mathrm{~S}+\mathrm{O}_{2}+1 / 2 \mathrm{H}_{2} \mathrm{O} \mathrm{NaOH}+1 / 2 \mathrm{Na}_{2} \mathrm{~S}_{2} \mathrm{O}_{3}
\end{aligned}
$$

One of the aims of this study was to investigate the regeneration of spent caustic, therefore, the amount of caustic was expected to increase. The present claim was confirmed by the experimental data. The reaction time variables had a significant effect on the regeneration process of spent caustic. It is mostly proffered to increase reaction time of the whole process. The error of the elementary model was less than the non-elementary one, but the concentration of spent caustic was decreased. It is obvious that the elementary model couldn't properly predict the components of spent caustic in Figure 4 . So, the experiments should be executed in a regime where diffusional resistance in gas and liquid phases could be ignored to find out the true kinetics (34). The kinetics of catalytic oxidation was carried out in the presence of a cobalt phthalocyanine (IVKAZ) catalyst. As shown in Figure 5, the thiosulfate content was significantly reduced, so that the experimental data as well as the results of elementary and non-elementary models' showed the same trend regarding to the studied kinetics. Figure 5 showed

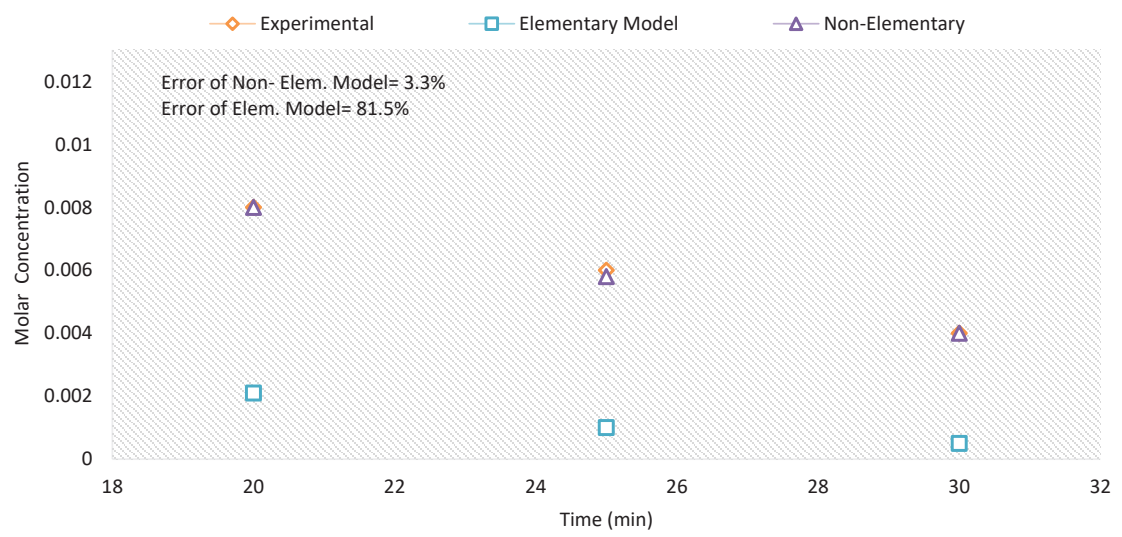

Figure 9. The results of $\mathrm{Na} 2 \mathrm{~S}$ obtained from experimental data and kinetic model. 
Table 3. Kinetic rate coefficient value for the reactions (1-5)

\begin{tabular}{lcc}
\hline $\begin{array}{l}\text { Kinetic rate } \\
\text { coefficient }\end{array}$ & $\begin{array}{c}\text { Elementary } \\
\text { model }\end{array}$ & Non-elementary model \\
\hline $\mathrm{k}_{1} \& \mathrm{k}_{1}^{\prime}$ & $\mathrm{k}_{1}^{\prime}=0.0001$ & $\mathrm{k}_{1}=0.0636$ \\
$\mathrm{k}_{2} \& \mathrm{k}_{2}^{\prime}$ & $\mathrm{k}_{2}^{\prime}=0.5658$ & $\mathrm{k}_{2}=0.0313$ \\
$\mathrm{k}_{3} \& \mathrm{k}_{3}^{\prime}$ & $\mathrm{k}_{3}^{\prime}=0.4999$ & $\mathrm{k}_{3}=0.0005$ \\
$\mathrm{k}_{4} \& \mathrm{k}_{4}^{\prime}$ & $\mathrm{k}_{4}^{\prime}=0.5000$ & $\mathrm{k}_{4}=2.0000$ \\
$\mathrm{k}_{5} \& \mathrm{k}_{5}^{\prime}$ & $\mathrm{k}_{5}^{\prime}=0.1000$ & $\mathrm{k}_{5}=0.3000$ \\
\hline
\end{tabular}

Table 4. The order of concentration in non-elementary model

\begin{tabular}{lllllll}
\hline \multicolumn{7}{c}{ Variables of non-elementary model } \\
\hline Item & $\mathrm{X}_{6}$ & $\mathrm{X}_{7}$ & $\mathrm{X}_{8}$ & $\mathrm{X}_{9}$ & $\mathrm{X}_{10}$ & $\mathrm{X}_{11}$ \\
Value & 4.994 & 4.993 & 4.996 & 8.029 & 4.574 & 5.195 \\
Item & $\mathrm{X}_{12}$ & $\mathrm{X}_{13}$ & $\mathrm{X}_{14}$ & $\mathrm{X}_{15}$ & $\mathrm{X}_{16}$ & $\mathrm{X}_{17}$ \\
Value & 10.00 & 0.0010 & 3.825 & 2.416 & 5.524 & 3.814 \\
\hline
\end{tabular}

that the error of non-elementary model was acceptable and could predict well. According to the Figure 5, thiosulfate had the highest concentration at the early times of the reaction. Due to the main oxidation reactions (1), decrease the amount of thiosulfate with time. Specially, by increasing the amount of oxygen and time, the sulfate content also increases $(35,36)$.

Oxygen participates in all five reactions, so it has more terms in the reaction equation. The results of elementary model for oxygen (despite the relatively low error compared to the other compounds), show that these models has not been able to accurately estimate the amount of oxygen in the reactor (Figure 6). The effects of oxygen concentration on the removal of sulfur compounds is directly related with evaluation of kinetics of reaction (16).

NaHS (Figure 7) was accelerated to thiosulfate in the reaction 3 and estimation was rather complex and unsatisfactory, because thiosulfate is an intermediate and unstable component. The kinetics of NaHS is predicted by non-elementary model slightly. The kinetic of the overall reaction tends to the consumption of sulfide. The unstable sulfur compound like hydrosulfide, is converted to thiosulfate and sulfate via increasing oxygen (35).

Mercaptide (NaSR) is considered rather stable under normal ambient temperature and pressure. The chemical oxidation of the mercaptide components to disulfides is actually slow (37). So, an appropriate catalyst is needed to increase the rate of conversion to disulfide. The disulfides are usually insoluble in the alkaline solution and can be separated easily.

According to Figure 9, the increase of reaction time helps approach the value of non-elementary model to the experimental amount and results in a low error at the end of the reaction time. Chemical oxidation of sulfide in alkaline media is usually generated thiosulfate (38).
As shown in Table 3, the orders of the non-elementary model are quite different from the elementary model. The non-elementary model seems to display really better results compared with the elementary one. The overall error of the non-elementary model was less than the elementary one. The comparison of others shows that the order of concentration of the reaction (4) was reasonable. One of the reasons that spent caustic is regenerated in these conditions is due to the value obtained in the reaction (4). According to the results obtained from the third reaction and Table 3-4 (kinetic coefficient and order of concentration), the effect of this reaction can be considered insignificant. The temperature and catalyst concentration are parameters which are prominent in the kinetic model. In this case, temperature and catalyst concentration are fixed. It is very interesting that kinetic coefficient of reactions (2) and (3) in the elementary model was higher than the non-elementary one. These reactions are related to NaHS components. This finding can be attributed to the order of oxygen in reactions (2) and (3). However, the regeneration of spent caustic was the main purpose. The value of oxygen order was lower than the elementary model order.

\section{Conclusion}

The conclusions drawn from this study can be resumed as follows:

In order to regenerate and treat the spent caustic, experiments were conducted via a catalytic air oxidation process in a bubble column reactor. A mathematical model was developed for regeneration of spent caustic in the batch system and it was investigated by the experiment. The temperature, catalyst concentration, $\mathrm{pH}$, and air flow are constant and reaction time from operating conditions is unstable.

It was found that heterogeneous cobalt phthalocyanine is a suitable catalyst for chemical oxidation of spent caustic under highly alkaline conditions.

The GA was used to predict the rate coefficient and kinetic order of component concentrations. The elementary and non-elementary models are considered for the whole of reactions. Based on the GA method, the nonelementary model has reasonable results comparison to the elementary one.

Fundamentally, when the materials are produced or consumed in different reactions the estimation is difficult via the elementary model. The errors of the objective function of elementary and non-elementary models was $134.96 \%$ and $3.01 \%$, respectively. It was also revealed that the non-elementary model is able to compute true values with the lowest error.

\section{Acknowledgments}

The authors would like to thank the University of Maragheh for their cooperation. 


\section{Ethical issues}

Ethical issues (plagiarism, informed consent, misconduct, data fabrication and/or falsification, double publication and/or submission redundancy) have been strictly observed by the authors.

\section{Competing interests}

The authors declare that they have no competing interest.

\section{Authors' contributions}

All authors contributed equally in all aspects of this research like data collection, analysis, and interpretation.

\section{References}

1. Abdul-Wahab SA, Al-Hajri A, Yetilmezsoy K. Impact of the ambient air quality due to the dispersion of non-methane organic compounds from Barka landfill. Int J Environ Sci Technol 2016; 13(4): 1099-108. doi: 10.1007/s13762-0160947-x.

2. Karimi A, Fatehifar E, Alizadeh R. Synthesis and characterization of nanostructured $\mathrm{CuO} / \mathrm{CeO} 2$ catalysts via ultrasound assisted techniques used for selective oxidation of CO. Iranian Journal of Chemical Engineering 2013; 10(3): 51-9.

3. Ahmad W. Neutralization of spent caustic from LPG plant at preem $\mathrm{AB}$ Goteborg [dissertation]. Goteborg, Sweden: Chalmers University of Technology; 2010.

4. Sheu SH, Weng HS. Treatment of olefin plant spent caustic by combination of neutralization and Fenton reaction. Water Res 2001; 35(8): 2017-21. doi: 10.1016/S00431354(00)00466-8.

5. Debellefontaine H, Chakchouk M, Foussard JN, Tissot D, Striolo P. Treatment of organic aqueous wastes: wet air oxidation and wet peroxide oxidation. Environ Pollut 1996; 92(2): 155-64. doi: 10.1016/0269-7491(95)00100-X.

6. Alnaizy R. Economic analysis for wet oxidation processes for the treatment of mixed refinery spent caustic. Environ Prog 2008; 27(3): 295-301. doi: 10.1002/ep.10261.

7. Jafarzadeh Haghighifard NA, Jorfi S, Ahmadi M, Mirali S, Kujlu R. Treatment of mature landfill leachate by chemical precipitation and Fenton advanced oxidation process. Environ Health Eng Manag 2016; 3(1): 35-40.

8. Karimi A, Fatehifar E, Alizadeh R, Ahadzadeh I. Regeneration and treatment of sulfidic spent caustic using analytic hierarchy process. Environ Health Eng Manag 2016; 3(4): 203-8. doi: 10.15171/ehem.2016.21.

9. Diaz de Tuesta JL, Garcia-Figueruelo C, Quintanilla A, Casas JA, Rodriguez JJ. Application of high-temperature fenton oxidation for the treatment of sulfonation plant wastewater. J Chem Technol Biotechnol 2015; 90(10): 183946. doi: $10.1002 /$ jctb.4494.

10. Oh SY, Shin DS. Degradation of spent caustic by Fenton and persulfate oxidation with zero-valent iron. J Chem Technol Biotechnol 2013; 88(1): 145-52. doi: 10.1002/jctb.3876.

11. Chavoshani A, Amin MM, Asgari G, Seidmohammadi A, Hashemi M. Chapter 8 - Microwave/Hydrogen Peroxide Processes. In: Ameta SC, Ameta R, eds. Advanced Oxidation Processes for Waste Water Treatment. Academic Press; 2018. p. 215-55.
12. Abdollahi Y, Zakaria A, Sairi NA. Degradation of high level $\mathrm{m}$-Cresol by zinc oxide as photocatalyst. CLEAN - Soil, Air, Water 2014; 42(9): 1292-7. doi: 10.1002/clen.201300451.

13. Golmohammadi S, Ahmadpour M, Mohammadi A, Alinejad A, Mirzaei N, Ghaderpoori M, et al. Removal of blue cat 41 dye from aqueous solutions with $\mathrm{ZnO}$ nanoparticles in combination with US and US-H2O2 advanced oxidation processes. Environ Health Eng Manag 2016; 3(2): 107-13. doi: 10.15171/ehemj.2016.08.

14. Massa A, Hernandez S, Ansaloni S, Castellino M, Russo N, Fino D. Enhanced electrochemical oxidation of phenol over manganese oxides under mild wet air oxidation conditions. Electrochim Acta 2018; 273: 53-62. doi: 10.1016/j. electacta.2018.03.178.

15. Kumar A, Verma N. Wet air oxidation of aqueous dichlorvos pesticide over catalytic copper-carbon nanofiberous beads. Chem Eng J 2018; 351: 428-40. doi: 10.1016/j. cej.2018.06.058.

16. Barge AS, Vaidya PD. Wet air oxidation of cresylic spent caustic - a model compound study over graphene oxide (GO) and ruthenium/GO catalysts. J Environ Manage 2018; 212: 479-89. doi: 10.1016/j.jenvman.2018.01.066.

17. Boczkaj G, Fernandes A, Makos P. Study of different advanced oxidation processes for wastewater treatment from petroleum bitumen production at basic $\mathrm{pH}$. Ind Eng Chem Res 2017; 56(31): 8806-14. doi: 10.1021/acs. iecr.7b01507.

18. Ahmadpour A, Haghighi Asl A, Fallah N. Synthesis and photocatalytic studies of $\mathrm{TiO} 2$-clinoptilolite on spent caustic wastewater treatment. Particul Sci Technol 2018; 36(7): 791-8. doi: 10.1080/02726351.2017.1302534.

19. Karimi A, Fatehifar E, Alizadeh R, Ahadzadeh I. Regeneration of spent caustic of olefin unit in a bubble column reactor: treatment and recovery optimization. Environ Prog Sustain Energy 2017; 36(2): 341-7. doi: 10.1002/ep.12433.

20. Sivapathasekaran C, Sen R. Performance evaluation of an ANN-GA aided experimental modeling and optimization procedure for enhanced synthesis of marine biosurfactant in a stirred tank reactor. J Chem Technol Biotechnol 2013; 88(5): 794-9. doi: 10.1002/jctb.3900.

21. Sowmiya N, Valarmathi B, Srinivasa Gupta N, Essaki Muthu P, Rajendran C. A novel genetic algorithm for solving machine part cell formation problem considering alternative process plans. Mater Today Proc 2018; 5(5 Pt 2): 13574-84. doi: 10.1016/j.matpr.2018.02.353.

22. Gen M, Cheng R. Genetic Algorithms and Engineering Design. Ashikaga, Japan: John Wiley \& Sons, Inc; 1997. doi: 10.1002/9780470172254.

23. Goldberg DE. Genetic Algorithms in Search, Optimization and Machine Learning. New York: Addison-Wesley; 1989.

24. Srinu Naik S, Pydi Setty Y. Optimization of parameters using response surface methodology and genetic algorithm for biological denitrification of wastewater. Int J Environ Sci Technol 2014; 11(3): 823-30. doi: 10.1007/s13762-0130266-4.

25. Kadri RL, Boctor FF. An efficient genetic algorithm to solve the resource-constrained project scheduling problem with transfer times: the single mode case. Eur J Oper Res 2018; 265(2): 454-62. doi: 10.1016/j.ejor.2017.07.027. 
26. Fatemi S, Masoori M, Bozorgmehry Boozarjomehry R. Application of genetic algorithm in kinetic modeling and reaction mechanism studies. Iranian Journal of Chemistry and Chemical Engineering 2005; 24(4): 37-46.

27. Balland L, Estel L, Cosmao JM, Mouhab N. A genetic algorithm with decimal coding for the estimation of kinetic and energetic parameters. Chemometr Intell Lab Syst 2000; 50(1): 121-35. doi: 10.1016/S0169-7439(99)00057-X.

28. American Public Health Association (APHA), Eaton, Andrew D, Water Environment Federation (WEF), American Water Works Association (AWWA). Standard Methods for The Examination of Water and Wastewater. 21st ed. Washington, DC: APHA, AWWA, WEF; 2005.

29. Rolia E, Chakrabarti CL. Kinetics of decomposition of tetrathionate, trithionate, and thiosulfate in alkaline media. Environ Sci Technol 1982; 16(12): 852-7. doi: 10.1021/ es00106a006.

30. Levenspiel O. Chemical Reaction Engineering. 3rd ed. USA: John Wiley \& Sons; 1999.

31. Soltani H, Shafiei S, Edraki J. Reactor network synthesis using coupled genetic algorithm with the quasi-linear programming method. Chem Biochem Eng Q 2016; 30(2): 199-211. doi: 10.15255/CABEQ.2014.2163.

32. Behroozsarand A, Soltani H. Hydrogen plant heat exchanger networks synthesis using coupled Genetic Algorithm-LP method. J Nat Gas Sci Eng 2014; 19: 62-73. doi: 10.1016/j. jngse.2014.04.015.

33. Mohammadbeigi K, Tajerian M. Demercaptanization of Distillate (DMD). Pet Coal 2004; 46(1): 17-22.

34. Jagushte MV, Mahajani VV. Insight into spent caustic treatment: on wet oxidation of thiosulfate to sulfate. J Chem Technol Biotechnol 1999; 74(5): 437-44. doi: 10.1002/(SICI) 1097-4660(199905)74:5<437::AID JCTB63>3.0.CO;2-1.

35. Kalantari H, Nosrati M, Shojaosadati SA, Shavandi M. Investigation of transient forms of sulfur during biological treatment of spent caustic. Environ Technol 2018; 39(12): 1597-606. doi: 10.1080/09593330.2017.1334707.

36. Nosrati M, kalantari H, Shojaosadati SA, Shavandi M. Optimization of factors affecting on sulfide oxidation from synthetic spent caustic by haloalkaliphilic Thioalkalivibrio versutus by focus on sodium ion effect: application of response surface methodology. Iranian Journal of Chemical Engineering 2017; 14(1): 74-87.

37. Ward C. Method for oxidizing mercaptans and mercaptide compounds from aqueous alkaline solutions and hydrocarbon distillates. US 4090954 A. 1978.

38. Millano EF, Sorber CA. Treatment of Thiosulfate-containing wastewater in activated sludge systems. J Water Pollut Control Fed 1986; 58(9): 917-23. doi: 10.2307/25043078. 